\title{
A ginástica laboral como prática integrativa numa organização pública de ensino superior
}

The labor gymnastics as integrative practice in a public organization of higher education

\author{
Yasmin Freitas Oliveira ${ }^{1}$ (i) Rosália Beber de Souza $^{2}(\mathbb{D}$ \\ ${ }^{1}$ Universidade Federal de Viçosa (UFV), Brasil, graduanda no curso de Secretariado Executivo Trilíngue (UFV), e-mail: \\ yasmin.oliveira@ufv.br \\ ${ }^{2}$ Universidade Federal de Viçosa (UFV), Brasil, Doutora em Administração (UFLA), e-mail: rosaliabeber@ufv.br
}

\begin{abstract}
RESUMO
A presente pesquisa tratou da utilização de práticas integrativas, com foco na ginástica laboral, como forma de amenizar o adoecimento no ambiente de trabalho. O principal objetivo foi verificar as percepções dos servidores públicos da área administrativa, lotados na Pró-Reitoria de Gestão de Pessoas da Universidade Federal de Viçosa, sobre as práticas integrativas e as melhorias proporcionadas à qualidade de vida dos mesmos, através da utilização da ginástica laboral. Para coleta de dados, foram aplicados dois questionários - através da plataforma Google Formulários - que foram enviados aos 60 servidores do órgão, obtendo-se 31 respostas no primeiro e 14 no segundo. Os dados foram analisados, à luz do referencial teórico e do Projeto SuperAção, e permitiram verificar que o ambiente de trabalho pode ser conceituado como espaço adoecedor, e que as práticas integrativas podem ser utilizadas para amenizar esse adoecimento, dessa forma, a ginástica laboral foi entendida por esses servidores como uma prática integrativa.
\end{abstract}

Palavras-chave: Práticas Integrativas. Ginástica Laboral. Adoecimento no trabalho.

\begin{abstract}
This research dealt with the use of integrative practices, focusing on labor gymnastics, as a way to soothe illness in the work environment. The main goal was to verify the perception of public employees in the administrative area, allocated in Pro-rectory of People Management at the Federal University of Viçosa, about the integrative practices and the improvements provided to their quality of life through the use of labor gymnastics. The data collection was applied by two elaborated questionnaires using Google Forms platform and sent to 60 organization employees, obtaining 31 answers in the first questionnaire and 14 in the last. After that, the data was analyzed in the light of theoretical reference and the project "SuperAção", it allowed to establish that the work environment can be classified as an illness environment, and the integrative practices can be used to soothe this illness and the labor gymnastics is understood by these employees as an integrative practice.
\end{abstract}

Keywords: Integrative Practices. Labor Gymnastics. Illness in Work Environment. 


\section{INTRODUÇÃO}

Inicialmente, o trabalho era utilizado para a pura sobrevivência, mas, com o passar do tempo, foi se modificando, até que chegamos ao que parece ser o nosso limite: vivemos em um cenário no qual "somos" o nosso trabalho, somos diariamente rotulados de acordo com as nossas atividades profissionais e o valor dos nossos salários, perdemos momentos significativos em troca de algumas horas a mais de trabalho e descuidamos, até, da saúde. O problema é que, muitas vezes, nós mesmos não percebemos o quanto isso nos afeta e nos anula em virtude do nosso "eu profissional". Colocamos toda a nossa energia em prol do nosso trabalho, até que um dia adoecemos, sem sequer entender o motivo. Isso é reflexo do sistema trabalhista caótico que o capitalismo nos oferece, o qual estamos aceitando.

O exposto nos leva a pensar que diversos fatores influenciam no surgimento de doenças causadas pelo ambiente laboral, inclusive a exposição diária a situações de estresse. No caso do nosso objeto de pesquisa, a Pró-Reitoria de Gestão de Pessoas (PGP) da Universidade Federal de Viçosa (UFV), lida-se com assuntos delicados, que englobam informações pessoais e sigilosas de seus servidores, além de questões de adoecimento deles e de seus familiares. Tal circunstância desenvolve no trabalhador o sentimento de que carrega muita responsabilidade, de que não pode falhar, pois, se isso acontece, prejudica o andamento dos processos que the cabem. Esses sentimentos se acumulam e geram sofrimentos que podem se manifestar em forma de doenças psicológicas, como depressão e síndrome do pânico, e/ou físicas, como dores musculares, articulares e cefaleias.

Encontramos nas práticas integrativas (PICS) uma maneira de amenizar esses efeitos do adoecimento laboral, pois elas agem de forma terapêutica, buscando o nosso equilíbrio, tanto prevenindo, quanto tratando os sintomas que percebemos em nosso corpo físico, emocional e mental. O foco desta pesquisa está em um ambiente de trabalho administrativo e, por isso, acreditamos que a ginástica laboral (GL) seja um bom ponto de partida para compreendermos essa relação trabalho-saúde, pois ela caracteriza-se pela utilização dos fundamentos da ergonomia e de diversas outras PICS, como a yoga, a ayurveda, a meditação e a bioenergética. Tendo em vista as inúmeras falhas existentes em nosso sistema trabalhista, especialmente na área administrativa, este trabalho se justifica como contribuição social e acadêmica que traz maior visibilidade para o adoecimento laboral, acompanhada da sugestão de uma possibilidade

Revista Expectativa, Toledo/PR, v.20, n. 2, p. 26-50, abr./jun., 2021. 
de solução para esse impasse para o mesmo. Outrossim, não encontramos uma quantidade significativa de estudos que abordem a ginástica laboral como uma prática integrativa. Dessa forma, como implicação prática para a presente área do saber, buscamos fornecer subsídios para que as instituições possam focar mais nessas técnicas, visando minimizar o adoecimento no ambiente de trabalho. Portanto, essa pesquisa pretende verificar as percepções dos servidores públicos da área administrativa, lotados na PGP/UFV, sobre as PICS e as melhorias proporcionadas à qualidade de vida deles, através da utilização da ginástica laboral. Como objetivos específicos, investigamos se o ambiente de trabalho pode ser conceituado como espaço adoecedor, se as PICS podem amenizar esse adoecimento e se a GL é entendida pelos servidores como uma prática integrativa.

Logo, sendo uma pesquisa de natureza qualitativa, usamos como metodologia a análise do fenômeno, pela ótica dos próprios servidores, com base no referencial teórico e no Projeto SuperAção. Vale ressaltar que este trabalho é fruto de uma densa pesquisa de campo e que, para fins de publicação no formato de artigo, tornou-se inviável maior aprofundamento das análises.

\section{REFERENCIAL TEÓRICO}

\subsection{O AMBIENTE DE TRABALHO COMO ESPAÇO ADOECEDOR}

A humanidade sempre utilizou da sua força para sobreviver, no entanto, o que vemos atualmente é uma supervalorização do trabalho, tornando-o muito além do provedor das nossas necessidades básicas, como acontecia nos primórdios da nossa existência. Tal mudança é um reflexo da supremacia do capitalismo, reforçada pelos efeitos da revolução industrial, que foram se modificando ao longo do tempo. Passamos por um momento pautado na produção artesanal, que contava com ambientes laborais predominantemente domésticos e encomendas com prazos menos exploratórios. Com o surgimento das máquinas, o ambiente laboral começou a se tornar o que conhecemos hoje: jornadas de trabalho excessivas, com a exigência de sempre produzir mais e em menor tempo para ter/ser mais, consequentemente, os funcionários tornam-se estressados, sem tempo para o convívio social e adoecendo por causa de seus ofícios. A diferença é que, agora, tudo isso está mascarado pelas leis trabalhistas e pelas formas veladas de burlá-las.

Revista Expectativa, Toledo/PR, v.20, n. 2, p. 26-50, abr./jun., 2021. 
Conforme exposto por Cardoso (2015), o contexto atual do ambiente laboral administrativo pode causar o adoecimento do trabalhador, uma vez que a "hipersolicitação" realizada aos trabalhadores pode ser vista através do estabelecimento de prazos cada vez menores, ritmos elevados e atividades muito repetitivas, o que acarreta na existência de riscos físicos, mentais e químicos.

Ainda segundo Cardoso (2015), para entender a ligação entre trabalho e saúde é preciso fundamentar-se nas experiências do próprio trabalhador, pois é dele que surge o trabalho, o esforço, o desgaste físico, mental e emocional; é dele o consequente adoecimento, acidente ou morte. Dessa forma, a relação entre o adoecimento do corpo e da mente deve ser entendida para prosseguirmos. Rabelo, Silva e Lima (2018) afirmam que a psicossomatização traduz-se na transmissão da aflição sofrida no ambiente de trabalho para sintomas físicos.

Ademais, Cardoso (2015) destaca também que, um olhar amplo sobre o processo saúdedoença possibilita que sejam explorados tanto os impactos, quanto os causadores do adoecimento laboral. Isso pode ser comprovado pelo que expõem Piolli, Silva e Heloani (2015), ao dizer que se analisarmos as ocorrências de estresse e/ou adoecimento podemos constatar sintomas físicos, como palpitações, dores na coluna e na garganta, arritmia, hipertensão, problemas renais, na vesícula e de pele; e também emocionais, que normalmente são relacionados com o excesso de preocupação, como choro fácil, irritabilidade, medo, indiferença, culpa, ansiedade, frustração, angústia, depressão, despersonalização, cansaço, nervosismo, falta de esperança/segurança/motivação, frieza, isolamento no trabalho, síndrome do pânico.

\subsection{PRÁTICAS INTEGRATIVAS COMO AMENIZADORAS DO ADOECIMENTO}

Devemos refletir também sobre a importância de as empresas estarem sempre atentas aos seus funcionários e às suas necessidades básicas: trabalho humanizado, ambiente adequado, confortável e dentro das normas de ergonomia, relações sociais saudáveis e, principalmente, à sua saúde, pois um empregado saudável apresenta maior disposição, satisfação e melhores resultados. Para alcançá-los, o empregador deve buscar formas de cuidar de seu funcionário, de evitar o seu adoecimento e de proporcionar maior prazer na realização de suas atividades

Revista Expectativa, Toledo/PR, v.20, n. 2, p. 26-50, abr./jun., 2021. 
profissionais. Existem diversas formas de se realizar essa tarefa, e uma delas é utilizando as PICS.

Souza e Luz (2009) expõem que o surgimento das PICS data do final dos anos 60 ao início dos anos 70 e deu-se a partir das necessidades que se manifestavam naquele momento. Dentre elas, vale destacar a ineficiência do sistema convencional de cuidado à saúde e as transformações culturais que passam a ver o homem não mais de forma holística, mas sim individualista; o que altera diretamente a percepção da saúde humana.

Saraiva et al. (2011) corroboram com a afirmação supracitada ao dizer que a evolução do processo saúde-doença passou por diversas transformações até chegar às PICS: perpassando pela visão de que estava ligado às forças espirituais, dogmas religiosos e, posteriormente, a fatores biológicos. As doenças são tratadas de forma isolada, adiante, inspirado pelos pensamentos de Descartes sobre o homem, surge o conceito da biomedicina que apresenta uma bifurcação entre corpo e mente. Nota-se, então, que os remédios por si só não resolvem ambas as questões: os sofrimentos do corpo são antepostos aos da alma/mente, levando à insatisfação com os meios convencionais e à busca por práticas alternativas que preencham essas lacunas.

Fischborn et al. (2016) afirmam que as práticas integrativas reforçam o propósito do cuidado total com a saúde, contemplando a tríade corpo-mente-alma. Isso porque as terapias integrativas suplementam os tratamentos médicos convencionais, agindo de forma menos invasiva ao organismo humano. Segundo o Ministério da Saúde do Governo Brasileiro (BRASIL, 20--), as PICS podem ser definidas como tratamentos terapêuticos, fundamentados em conhecimentos tradicionais, que buscam prevenir doenças como a depressão e, em alguns casos, até tratar doenças crônicas.

Existem hoje muitas práticas integrativas, que se complementam, podendo uma ter características das outras e serem utilizadas de forma individual ou conjunta; entre elas podemos citar algumas, que inclusive fazem parte das 29 técnicas oferecidas atualmente pelo Sistema Único de Saúde (SUS): aromaterapia, arteterapia, bioenergética, biodança, geoterapia, hipnoterapia, homeopatia, imposição de mãos, medicina tradicional chinesa, meditação, musicoterapia, osteopatia, ozonioterapia, fitoterapia, quiropraxia, reflexoterapia, reiki, terapia de florais e yoga (BRASIL, 20--). 


\subsection{A GINÁSTICA LABORAL ENTENDIDA COMO UMA PRÁTICA INTEGRATIVA}

A ideia de ergonomia é muito importante para a compreensão da ginástica laboral e, segundo a Associação Brasileira de Ergonomia (ABERGO), ela permite proporcionar a melhoria da relação homem-ambiente laboral (ABERGO, 20--). Em concordância, o Centro de Reabilitação Profissional de Gaia (CRPG) apresenta a ergonomia como a ciência que avalia o diálogo entre o homem e o trabalho por ele realizado, buscando aumento da produtividade, lucro e eficiência organizacional, por meio da qualidade de vida no trabalho (QVT), considerando-se para isso questões como movimentos e posturas corporais tomados pelos funcionários, equipamentos de trabalho e fatores ambientais e físicos (CRPG, 2012).

Embora a ginástica laboral não esteja na lista das 29 práticas integrativas oferecidas pelo SUS, ela é um exemplo dessa interação entre as PICS, pois se utiliza, por exemplo, das "ásanas" (posturas corporais) pertencentes tanto à ayurveda quanto à yoga, que proporcionam flexibilidade e alongamento ao corpo, estando assim, diretamente ligada a ergonomia, tão presente na GL (BRASIL, 20--). Vale-se também das ideias da bioenergética e da meditação no que tange aos movimentos corporais sincronizados com a respiração, em busca da libertação de tensões e melhor expressão de sentimentos. Bem como tem o objetivo semelhante ao da quiropraxia, ou seja, correção de problemas posturais e alívio de dores físicas (BRASIL, 20--). Outrossim, pode ser oferecida em conjunto com o uso de práticas como a aromaterapia e a musicoterapia que dizem respeito à harmonização do ambiente, proporcionando relaxamento, leveza e diminuição do estresse causado pela agitação do ambiente laboral (BRASIL, 20--).

Martins (2000) afirma que a ginástica laboral atua de forma terapêutica e preventiva, buscando a redução dos acidentes de trabalho, prevenção da fadiga muscular e de doenças causadas por traumas cumulativos, além da correção de problemas posturais. A autora ainda diz que a GL compreende exercícios e atividades executados no próprio ambiente de trabalho, de natureza leve, com breve extensão e que proporcionem maior integração no meio laboral, podendo ser realizada antes (preparatória), durante ou após a jornada de trabalho (compensatória), aumentando a disposição do trabalhador para realizar suas tarefas (MARTINS, 2000).

Martins (2000) indica também que o trabalhador não possui rendimento constante ao longo de sua jornada: o início das atividades configura uma adaptação progressiva do corpo às

Revista Expectativa, Toledo/PR, v.20, n. 2, p. 26-50, abr./jun., 2021. 
condições do trabalho; após isso, alcança-se o apogeu da sua produtividade, com constância da mesma por aproximadamente duas horas; passando esse estágio, nota-se o surgimento do cansaço e o declínio da produtividade. Assim, a realização de pausas pode diminuir esses traços de improdutividade e equilibrar satisfatoriamente a performance do funcionário.

A implementação dessa prática não é de difícil acesso, podendo ser oferecida em organizações de pequeno a grande porte. Um artigo publicado pela Revista Proteção (Capital..., 1995 apud Martins, 2000, p. 28), apresenta as etapas para uma implantação de sucesso da mesma: a primeira consiste em realizar uma análise de fatores como a QVT, ergonomia e aptidão física dos funcionários, adequando esses pontos à atividade física oferecida. Posteriormente, deve-se estruturar o programa, pensando-se na melhor forma de mostrar ao trabalhador a importância de tais atividades, motivando-o a ter comprometimento, aceitação e dedicação com a proposta. A terceira fase informa os servidores sobre como uma postura ruim pode prejudicar sua saúde e como a prática regular de atividades físicas pode auxiliar. A partir de então, implementa-se o projeto e realiza-se a constante avaliação dos resultados, observando seus reflexos na saúde do trabalhador e na sua produtividade.

No que tange aos investimentos com a prática, Poletto (2002) observa que não são altos, porém existe resistência por parte dos empresários/chefes, especialmente quanto às pausas (normalmente de 10 a 15 minutos) para realização das atividades no horário de trabalho. A relação custo-benefício é pautada, principalmente, na questão da produtividade do trabalhador, ou seja, um trabalhador saudável e satisfeito além de produzir mais, adoece com menor frequência, evitando assim as despesas de afastamento, medicamentos, consultas e substituição de funcionários, compensando, portanto, as pausas citadas (POLETTO, 2002).

Segundo Poletto (2002), o investimento maior está na contratação de profissionais capacitados para a elaboração, coordenação e implantação do projeto. O mesmo deve, preferencialmente, ser criado por uma equipe especializada, formada por médicos do trabalho, engenheiros e técnicos de segurança do trabalho, fisioterapeutas e graduados em educação física, sendo estes últimos os responsáveis por executar os exercícios juntos ao quadro de funcionários (POLETTO, 2002).

A partir do exposto, observa-se que, entre as inúmeras práticas integrativas existentes, a ginástica laboral é bastante adequada ao ambiente de trabalho administrativo, dado que conta comumente com espaço e tempo reduzidos para a realização das práticas e contém uma grande

Revista Expectativa, Toledo/PR, v.20, n. 2, p. 26-50, abr./jun., 2021. 
carga de fatores estressantes. Além disso, possui uma relação custo-benefício bastante favorável à empresa.

\section{PROCEDIMENTOS METODOLÓGICOS}

Esta é uma pesquisa de natureza qualitativa. Consoante com Godoy (1995), essa ótica permite interpretar melhor um fenômeno se ele for analisado no contexto em que acontece e, para isso, quem o estuda deve, em campo, compreendê-lo a partir das percepções dos indivíduos nele incluídos, atentando-se a todas as opiniões dispostas. Em complemento, Moreira (2002) destaca seis características da pesquisa qualitativa: (1) o pesquisador deve focalizar na interpretação que os participantes têm do fenômeno estudado; (2) desmistifica a ideia de que para ser uma pesquisa científica deve ser objetiva, uma vez que a essência do estudo qualitativo está na presença da subjetividade das perspectivas dos participantes; (3) deve haver flexibilidade na condução do estudo, considerando-se a impossibilidade de definir, com exatidão, em seu início, quais caminhos serão tomados; (4) deve-se enfatizar o processo ao invés do propósito predefinido, ou seja, compreender o fenômeno analisado; (5) refere-se à ligação existente entre as experiências das pessoas envolvidas, que estão intimamente relacionadas com o contexto no qual estão inseridas e o comportamento das mesmas; (6) admite que há uma relação de influência entre os sujeitos da pesquisa: a situação pesquisada influencia o pesquisador, assim como ele a influencia.

Para a análise das entrevistas, optamos pelo estudo das narrativas. A narratologia corresponde à designação, dada por Todorov (1969), à análise da narrativa. Para Alves e Blikstein (2010), conforme a tradição linguística francesa, a narrativa pode ser definida como o discurso que se refere a uma temporalidade, passada ou imaginada, com relação ao momento da enunciação. Assim, num primeiro momento, podemos entender também a narrativa como um discurso que trata das ações ocorridas no passado. Como define Labov (1972), a narrativa é um método de recuperar a experiência passada pela combinação de uma sequência verbal de causas a uma sequência de eventos, os quais realmente aconteceram. Temos como importante, então, o fator da temporalidade como característica da narrativa. A análise da narrativa procura entender o texto por sua totalidade, sua grandeza, partindo de suas peculiaridades.

Revista Expectativa, Toledo/PR, v.20, n. 2, p. 26-50, abr./jun., 2021. 
Segundo Freitag (2018), a amostra de pesquisa, quando feita por julgamento, refere-se à apreciação do investigador de campo quanto à seleção de participantes que possam trazer elucidações de confiança, a fim de alcançar os objetivos do projeto. Nesse caso, o público-alvo foi definido a partir da observação de quais setores da UFV participavam do Projeto SuperAção e qual deles possui maior número de funcionários. Escolheu-se, assim, estudar e verificar quais são as percepções dos servidores públicos da área administrativa, lotados na PGP/UFV, sobre as PICS e as melhorias proporcionadas à qualidade de vida deles, através da utilização da ginástica laboral. Para isso, inicialmente foi realizada uma pesquisa bibliográfica dos autores dispostos no referencial teórico deste trabalho, com o intuito de contextualizar o tema pesquisado, juntamente com a revisão do Projeto SuperAção. A revisão literária/bibliográfica, segundo Miguel (2007), é uma importante ferramenta metodológica, pois auxilia na identificação, conhecimento e acompanhamento de evoluções dos estudos na área de pesquisa escolhida, além disso, afirma ainda que ela proporciona a identificação de questões para possíveis pesquisas futuras.

Como ferramenta de coleta de dados, foi utilizada a plataforma online "Google Formulários". Conforme expõem Faleiros et al. (2016), as pesquisas virtuais estão sendo frequentemente utilizadas, pois apresentam maior agilidade na coleta de dados frente aos métodos tradicionais, como entrevistas presenciais e questionários impressos, além de possuírem custos econômicos mais viáveis. Ademais, pelo fato dessa pesquisa ter sido realizada em um momento de pandemia, no qual o distanciamento social é a melhor forma de prevenção do contágio, essa foi a escolha mais adequada. Foram, portanto, aplicados dois questionários semiestruturados com questões objetivas, de múltipla escolha e discursivas, com links enviados via e-mail. Além disso, os participantes assinaram o Termo de Consentimento Livre e Esclarecido, que foi enviado utilizando a mesma plataforma do "Google Formulários", ambos elaborados pela acadêmica pesquisadora.

O primeiro questionário, composto por 17 questões, foi enviado aos 60 servidores da unidade, obtendo-se 31 respostas voluntárias entre os dias 27 de fevereiro e 06 de março de 2020. Os 29 servidores que não responderam aos dois primeiros e-mails de convite para a participação nesse estudo foram descartados da amostra de pesquisa por falta de contato em tempo hábil. A escolha das perguntas desse questionário deu-se pelo critério de julgamento, 
uma vez que visava traçar o perfil demográfico dos servidores respondentes e conhecer a opinião desse grupo sobre a GL e a prática constante de exercícios físicos.

Após traçar esse perfil, foi enviado o segundo questionário, contendo 11 questões, também elaboradas a partir do critério de julgamento, sendo agora destinadas somente aos 14 servidores que afirmaram participar da ginástica laboral. Entre os dias 7 e 13 de março, 10 respostas foram obtidas e, assim como ocorreu na primeira etapa, os 4 servidores que não responderam foram excluídos dessa segunda fase da pesquisa, por falta de retorno aos e-mails em tempo hábil. Esta etapa objetivou entender as percepções dos servidores sobre as práticas integrativas; saber se eles possuem algum conhecimento prévio sobre elas; se já participaram de alguma outra PIC; entender o que os motiva a participar da GL e se a consideram como uma prática integrativa; descobrir se já sentiram os sintomas do adoecimento no trabalho; como percebem sua vida laboral e o sistema trabalhista atual.

O Programa de Qualidade de Vida para Servidores é uma iniciativa do Serviço de Saúde Ocupacional e Qualidade de Vida (SSQ), da PGP, em parceria com o Departamento de Educação Física (DES) da UFV, e está em vigor desde 2006, sendo reformulado pela última vez em 2016. Conhecido como Projeto SuperAção, tem por objetivo promover a melhoria na qualidade de vida dos servidores, combatendo os efeitos negativos do trabalho, prevenindo acidentes e doenças ocupacionais e promovendo a educação em saúde, por meio de atividades físicas orientadas e gratuitas, entre elas a musculação, caminhada orientada, ginástica localizada, ginástica terapêutica e ginástica laboral, sendo essa o nosso foco (PGP-UFV, 20--).

Antes de iniciar as práticas no setor, foi realizada uma análise do perfil dos servidores e do ambiente, assim como dos sintomas sentidos por eles. Em seguida, elaborou-se um plano de ação direcionado para as atividades laborais exercidas pelos funcionários, que é executado por acadêmicos do curso de Educação Física, supervisionados por professores do DES, quando solicitados pelos alunos. Os horários e frequência das atividades variam de acordo com a disponibilidade dos bolsistas, mas as sessões duram em média 15 minutos e são realizadas em grupos. Há uma avaliação periódica, por meio de questionário aplicado aos participantes, para apontar se as metas estão sendo alcançadas e se o projeto necessita de alguma modificação. Inclusive, no primeiro formulário aplicado nessa pesquisa, foram questionados quanto à eficácia do projeto.

Revista Expectativa, Toledo/PR, v.20, n. 2, p. 26-50, abr./jun., 2021. 
Além disso, os participantes são estimulados a praticarem atividades físicas fora do horário de trabalho, para que esse cuidado com a saúde seja levado para todos os âmbitos da vida, preparando-os melhor para lidar com as questões cotidianas. Essa também foi uma questão levantada no primeiro formulário aplicado, ao perguntar se os participantes praticavam alguma atividade física além da GL. A análise dos dados foi realizada à luz do referencial teórico, buscando encontrar uma relação de "expectativa (teoria) X realidade (prática)".

\section{APRESENTAÇÃO E ANÁLISE DOS RESULTADOS}

\subsection{APRESENTAÇÃO DO PERFIL DOS PARTICIPANTES}

A primeira etapa da coleta de dados consistiu na aplicação de um formulário com 17 questões, que foi enviado para os 60 servidores da unidade, obtendo 31 respostas. Este visava conhecer a opinião e as experiências dos servidores sobre a ginástica laboral e traçar o perfil dos mesmos, gerando o seguinte panorama: 18 homens e 13 mulheres, sendo uma pessoa com menos de 25 anos, nove entre 26 e 35 anos, quinze entre 36 e 45 anos, cinco entre 46 e 55 anos e uma acima de 56 anos. Desses 31 servidores, dois atuam no setor administrativo há menos de 01 ano, seis entre 01 e 02 anos, três entre 03 e 05 anos, dez entre 06 e 10 anos, quatro entre 11 e 15 anos, dois entre 16 e 20 anos e quatro há mais de 20 anos. Quanto aos cargos exercidos, observa-se uma maioria de 16 auxiliares administrativos, somados a 3 técnicos em segurança do trabalho, 2 engenheiros de segurança do trabalho, 2 administradores, 2 psicólogos, 1 assistente social, 1 contador, 1 chefe da seção de documentação e arquivo, 1 médico do trabalho, 1 fisioterapeuta e 1 técnico em assuntos educacionais. Tal panorama nos ofereceu a oportunidade de estudarmos o fenômeno pretendido por óticas, estilos de vida e experiências bastante variados, criando uma base de dados rica e abundante, além de confirmar o que apontou Cardoso (2015) ao dizer que, para entender a ligação entre trabalho e saúde, é preciso fundamentar-se nas vivências do próprio trabalhador, pois foram justamente os testemunhos desses servidores que nos ajudaram a estabelecer uma relação de "expectativa (teoria) $\mathrm{X}$ realidade (prática)".

Dos 31 servidores, 17 afirmam não participar da GL. Desses, 1 diz ser por falta de força de vontade, mas reconhece a importância da atividade, 4 justificam dizendo que praticam outras

Revista Expectativa, Toledo/PR, v.20, n. 2, p. 26-50, abr./jun., 2021. 
atividades físicas diariamente; 1 alega que por ter tido problemas de saúde perdeu o ritmo para atividades físicas, além de não se adequar ao horário em que a GL é ofertada, juntamente com mais 2 colegas que também não agradam do horário; 5 não apresentam justificativa para a não participação; 2 certificam que não praticam pois não gostam; 2 não participam por terem problemas de saúde que não permitem a execução dos exercícios. Os outros 14 afirmam participar do projeto e seguem na pesquisa. O tempo que os participantes alegam realizar a GL foi bastante variado: um afirma participar há 6 meses; três há 1 ano; três há 2 anos; dois há 3 anos; dois há 4 anos; um há 6 anos; um há 10 anos e um alega não saber o tempo certo.

Do total de participantes que permanecem na pesquisa, $40 \%$ afirmam não ser frequentes nas atividades ofertadas e $60 \%$ raramente faltam, mas todos os 14 justificam suas faltas pela sobrecarga de serviços e impossibilidade de parar o trabalho. Tais dados nos revelam que, por mais que o empregador se mostre preocupado com a saúde e QVT de seus empregados ao ofertar a GL, ele não tem criado as condições ideais para que todos possam participar dela efetivamente e, assim, ao invés de maior produtividade, ele gera mais cansaço e desmotivação. Esse posicionamento pode ser confirmado por Martins (2000), ao indicar que o trabalhador não possui rendimento constante ao longo de sua jornada e, por isso, a realização de pausas pode diminuir esses traços de improdutividade e equilibrar a performance do funcionário. Desses 14 participantes, somente 4 não praticam outras atividades físicas além da GL. Os outros 10 apresentam uma vida bastante ativa, com uma boa frequência na realização de exercícios físicos, como pilates, musculação, ciclismo, entre outros, demonstrando assim que, $71 \%$ desses servidores têm consciência da importância de atividades físicas para promover a melhoria da qualidade de vida.

Nas questões de número 07, 08, 13, 14, 15, 16 e 17 do primeiro questionário, esses 14 participantes apresentam suas percepções sobre a ginástica laboral ofertada pelo Projeto SuperAção. Quando questionados sobre suas motivações para participar dessa atividade, muitas das respostas que foram dadas se assemelham, ou se complementam, nos indicando que, além de se preocuparem com sua qualidade de vida, são conhecedores dos inúmeros benefícios que essa prática pode trazer: três participantes afirmam que são motivados pela melhoria que a atividade proporciona à saúde, tanto física quanto mental; dois citam a socialização com os colegas de trabalho; o participante 2 afirma que se sente motivado pela preparação do corpo para a jornada de trabalho; enquanto o participante 3 diz que ela proporciona "uma sensação

Revista Expectativa, Toledo/PR, v.20, n. 2, p. 26-50, abr./jun., 2021. 
de relaxamento corporal e descanso mental das rotinas administrativas, mesmo que por alguns minutos." (participante 3); quatro deles apontam a melhoria nas condições de trabalho, no bemestar no ambiente laboral e na disposição para trabalhar e cinco afirmam que ela contribui para a melhoria e correção postural e previne problemas ergonômicos. Conforme visto, o conceito de ergonomia está muito presente na GL e todas essas motivações citadas pelos participantes vão ao encontro da definição para esse termo dada pela ABERGO, isto é, ela permite proporcionar a melhoria da relação homem-ambiente laboral (ABERGO, 20--).

\subsection{GINÁSTICA LABORAL COMO AUXILIAR NA QUALIDADE DE VIDA NO TRABALHO?}

A partir desse momento da pesquisa, lidamos com o surgimento de dois grupos: um que considera que a prática da GL auxilia na redução do adoecimento no ambiente laboral e outro que considera que ela não auxilia. Ao serem indagados se sentem dores no corpo, quais são elas e se reduzem com a prática da GL, apenas 4 afirmam não sentir dores. Com esse dado, comprovamos que o adoecimento laboral é uma realidade e precisa ser melhor analisado. Tal afirmação condiz com Cardoso (2015), quando destaca que um olhar amplo sobre o processo saúde-doença possibilita que sejam explorados tanto os impactos, quanto os causadores do adoecimento laboral.

Dos 10 participantes que dizem sentir dores, somente um afirma que sente, ocasionalmente, dores na coluna, mas que não é frequente às práticas da GL e, por isso, não sabe dizer se a mesma proporciona melhorias. Já o participante 10 aponta que sente dores no joelho, devido a um quadro de lesão no LCA (ligamento cruzado anterior) e que, por isso, não pode realizar alguns movimentos da GL, consequentemente, não notando assim a minimização da dor por ela. Por sua vez, o participante 8 afirma que sente dores o tempo todo, mas não as especifica e conclui que a GL as alivia apenas momentaneamente, enquanto o participante 18 declara que sente dores periodicamente, mas, sem identificá-las, diz que, diretamente, a GL não proporciona melhorias e o participante 12 reconhece que pratica a musculação e a mesma, às vezes, lhe causa dores do esforço, que são, por vezes, aliviadas pela prática da GL. Esses participantes, que não acreditam na eficácia da GL, representam 50\% dos que sofrem sintomas físicos do adoecimento laboral; um número que seria bastante expressivo, mas não o é, pois

Revista Expectativa, Toledo/PR, v.20, n. 2, p. 26-50, abr./jun., 2021. 
apresenta como justificativas motivos relacionados à falta de frequência necessária para sentir os efeitos. Os outros $50 \%$ desses participantes citam dores constantes nas costas, ombros, pescoço, coluna, pernas, lombar e mãos e asseguram que a GL auxilia sim na redução dessas dores.

Foram questionados também se notaram melhorias em suas saúdes/vidas após iniciar a prática de ginástica laboral. Apenas dois participantes apresentam respostas parcialmente negativas para essa pergunta, o participante 18 afirma: "Não necessariamente. Meu condicionamento físico é bom, então não senti diferenças, talvez tenha melhorado um pouco mobilidadelflexibilidade. Sem alterações nas relações interpessoais e na saúde mental" (participante 18).

O participante 14 afirma que não notou melhoria, pela pouca frequência, mas completa que quando participa é muito bom. Os outros 12, representando $85 \%$ dos participantes, responderam positivamente, acrescentando que percebem sim melhorias. No que se refere à saúde mental/emocional, os servidores indicaram que perceberam redução de estresse, maior interação com os colegas e descanso mental. Quanto à saúde física, observaram aumento de flexibilidade, condicionamento físico, disposição e bem-estar. Tudo isso nos recorda o que Martins (2000) afirma sobre a GL atuar de forma terapêutica e preventiva, em busca da correção postural, redução dos acidentes laborais, prevenção da fadiga muscular e de doenças causadas por traumas cumulativos.

Buscou-se entender também se a GL tem auxiliado no desenvolvimento e execução de suas tarefas profissionais diárias. De acordo com a pesquisa, $22 \%$ dos participantes alegam que não e os outros $78 \%$ afirmam que sim, principalmente através do aumento da disposição e da concentração, maior desempenho, redução de desconfortos e tensão durante as tarefas, auxílio na velocidade de digitação e prevenção de dores. Isso nos indica que, mesmo que alguns participantes não sintam melhorias diretas em suas dores físicas, $78 \%$ deles apresentam resultados positivos com a prática em algum âmbito da vida, o que nos leva a crer que é por isso que continuam participando do projeto e buscando melhorias em seu estilo de vida.

Foi solicitado também que definissem a ginástica laboral. Obtivemos respostas bastante satisfatórias, as quais demonstram que os servidores sabem do que se trata e reconhecem a importância dessa atividade, como pode ser visto na seguinte definição dada pelo participante 3: "Defino a GL como toda atividade física realizada no ambiente de trabalho com a finalidade

Revista Expectativa, Toledo/PR, v.20, n. 2, p. 26-50, abr./jun., 2021. 
de melhoria no condicionamento físico e psicológico" (participante 3). Demonstrando pesquisa e interesse pelo assunto, em concordância com a definição dada por Martins (2000), o participante 21 conceitua: "Atividade física leve, de curta duração, realizada no local de trabalho, com o objetivo de prevenir problemas ergonômicos associados à má postura ou posturas assumidas por um período de tempo considerável". Destacam também a sua característica de atividade de descontração e integração com os colegas de trabalho; "Como uma pausa para recarregar as energias" (participante 30 ). De forma geral, caracterizam a GL como uma ferramenta importante e necessária para auxiliar na saúde e QVT, uma excelente atividade para o corpo e a mente, a qual promove bem-estar e saúde no ambiente laboral, alguns consideram, inclusive, que ela deveria ser obrigatória.

Nas duas últimas questões, abriu-se espaço para que os participantes avaliassem a ginástica laboral ofertada pelo Projeto SuperAção, permitindo que sugerissem as alterações as quais achassem necessárias e fizessem comentários livres a respeito das suas percepções sobre a GL. Em geral, avaliaram-na de forma positiva - "útil”, "eficaz”, "excelente”, "muito boa”, "ótima". O participante 20 afirma que "o oferecimento da ginástica laboral no ambiente de trabalho é um cuidado que o órgão tem com a saúde das pessoas que nele trabalham, que tem efeitos positivos tanto para o servidor quanto para o órgão” (participante 20).

Essa colocação nos remete ao que já foi discutido nesse trabalho sobre a relação custobenefício para a implementação de um projeto de GL nas empresas, especialmente quanto ao aumento da produtividade. Conforme Martins (2000) e também o CRPG (2012), cuidando do seu funcionário o empregador está evitando gastos com adoecimentos e tornando-o mais produtivo, trazendo, assim, mais lucros para sua empresa. Alguns dizem que não fariam alterações, outros citam que gostariam que ela fosse ofertada com maior frequência e regularidade, com mais opções de horários, para que pudesse atender um maior número de servidores; o participante 14 sugere ainda que o projeto e os seus resultados sejam mais divulgados. Os estudos de Martins (2000) nos apresentaram em nosso apoio teórico as etapas que um projeto como esse deve seguir para ser implementado e ter sucesso. As opiniões desses servidores nos indicam, mais uma vez, que eles percebem os benefícios que a GL pode proporcionar em suas vidas e o desejo que eles têm de praticar e disseminar a atividade, ou seja, no Projeto SuperAção as etapas que consistem na conscientização e informação do público alvo foram bem articuladas e obtiveram sucesso, mas enfrentam como empecilho a real 
disponibilidade de tempo cedida pelo empregador para que possam praticá-la, pecando, então, na etapa referente à avaliação dos resultados e correção dos erros.

Destacam também que é um projeto muito importante, que deve continuar existindo e sendo aperfeiçoado. Por sua vez, o participante 3 atesta que o projeto é eficaz quanto aos exercícios físicos, mas que deixa a desejar no que tange ao descanso mental e integração da equipe: "Sugiro que o projeto crie dinâmicas de grupo e outros meios que proporcione o descanso mental e a integração da equipe” (participante 3). Esse é um feedback bastante interessante, pois demonstra a visão que o servidor tem da totalidade que uma prática integrativa carrega pautada na tríade, anteriormente citada pela ótica de Fischborn et al. (2016): mente, corpo e alma devem ser trabalhados juntos para que encontrem o equilíbrio necessário para manutenção da saúde e qualidade de vida. Além de sugerir com essa colocação que está aberto e considera interessante a complementação com outras práticas integrativas que auxiliem nessas questões levantadas, podemos pensar aqui, por exemplo, na meditação e yoga. Outros servidores, embora considerem boa a GL ofertada, comentam o fato de julgarem os exercícios pesados para o contexto: "Considero um excelente programa, mas sugiro que as atividades sejam mais leves considerando que frequentemente são realizados exercícios que exigem muito esforço físico" (participante 21); “Às vezes falta um acompanhamento aos estagiários, para desenvolver exercícios específicos" (participante 8); estes últimos são corroborados pelo colega, que considera a GL

Boa. No entanto, alguns instrutores abordam a ginástica de forma inadequada ao meu
ver. Porque a atividade é oferecida apenas uma ou duas vezes na semana e eles
colocam atividades como abdominais e outros exercícios mais pesados que não são
adequados e nem estamos vestidos adequadamente com roupas de ginástica. Quando
o instrutor dá muita ênfase nessas atividades acaba afastando os servidores e há poucas
pessoas participando, estão desinteressadas. Além disso, o estagiário sempre passava
os mesmos exercícios. Os primeiros instrutores que conheci tinham uma abordagem
diferenciada, preocupavam-se mais com alongamento e correção postural. Eu
considerava as aulas mais eficientes para o propósito da ginástica laboral e meus
colegas se sentiam mais motivados a participar, o grupo participante era maior. Os
estagiários devem ser melhor orientados para corrigir o que foi falado e motivar mais
servidores a participarem (participante 6).

As últimas três colocações acima possuem uma grande riqueza de informações, principalmente no que tange às percepções que esses servidores têm sobre a forma como as aulas são ministradas. Os três relatos abordam a insatisfação deles com os tipos de exercícios que são passados, o que marca novamente o nível de conhecimento que esses funcionários têm

Revista Expectativa, Toledo/PR, v.20, n. 2, p. 26-50, abr./jun., 2021. 
sobre a atividade que estão participando, ou seja, estão ali compreendendo o processo de melhoria da qualidade de vida no trabalho como um todo, em suas especificações e objetivos, conseguem apontar o que precisa ser aperfeiçoado para que atinja sua eficiência e eficácia.

Ademais, percebem que há uma falha na assistência profissional da atividade, pois conforme o participante 8 assinala, falta o acompanhamento adequado dos estagiários, o que é validado pelo participante 6 quando sinaliza que há uma clara divergência entre as práticas ministradas por um grupo e outro de estagiários. E esse é um erro que não pode ocorrer ao se implementar um projeto como esse, uma vez que a prática realizada de forma incorreta, inadequada, em níveis de dificuldade muito acima do ideal, além de afastar o público-alvo, pode ter um efeito contrário ao que se deseja, isso é, pode acarretar os problemas que se busca evitar com sua aplicação.

É exatamente por isso que Poletto (2002) afirma que o investimento maior no oferecimento da GL está na contratação de profissionais capacitados para a elaboração, coordenação e implantação do projeto em si; fisioterapeutas e profissionais da educação física são essenciais durante a prática da atividade. Não se exclui, portanto, a participação dos estagiários, pois sabemos que esta é uma experiência necessária para sua formação acadêmica, mas ele deve sempre ser supervisionado para garantir tanto a qualidade de seu aprendizado quanto a da segurança do servidor que participa da atividade.

\subsection{OUTRAS PRÁTICAS INTEGRATIVAS PODEM AUXILIAR NA SAÚDE DO TRABALHADOR?}

O segundo questionário aplicado, contendo 11 questões, foi enviado aos 14 servidores que afirmaram, na primeira etapa, participar da ginástica laboral ofertada pelo Projeto SuperAção. Obteve-se 10 respostas voluntárias. Com esse segundo momento pretendeu-se entender as percepções dos servidores sobre as PICS em geral, saber se eles possuem algum conhecimento prévio sobre elas, se já participaram de alguma outra PIC, conhecer melhor suas motivações para participar da GL e se a consideram como uma prática integrativa, perceber se já sentiram os sintomas físicos e emocionais do adoecimento no ambiente de trabalho, entender como percebem sua vida laboral e o sistema de trabalho no qual estamos inseridos.

Revista Expectativa, Toledo/PR, v.20, n. 2, p. 26-50, abr./jun., 2021. 
Desses 10 servidores que responderam à pesquisa, 8 consideram que têm uma boa vida laboral e 2 a classificam como ótima. A partir desse panorama, pergunta-se sobre os sintomas físicos que já tiveram do adoecimento no ambiente de trabalho, se foram realizados tratamentos e se foram episódios isolados ou repetitivos. Podendo uma pessoa marcar mais de um sintoma, foi constatado que: 6 alegaram sentir dores musculares, 5 dores na coluna, 2 arritmia, 2 problemas digestivos/gástricos, 2 problemas de pele, 1 problemas respiratórios, 1 dores nas mãos e 1 dores nos pulsos.

O participante 3 afirmou que sofreu com dores na coluna, musculares e problemas de pele. Quanto à frequência e tratamentos diz:

\footnotetext{
Não cheguei a ter adoecimentos longos, a maioria melhorou em até uma semana, uma vez adotei medidas para reduzir o ritmo, seja tirando folga, seja redefinindo as prioridades, com o objetivo de reduzir o estresse e consequentemente mitigar os sintomas que de certa forma, estão relacionados com a ansiedade. Os sintomas relacionados com dores musculares e na coluna foram reduzidos com medicamentos, rotina de exercício laboral e readequação ergonômica (participante 3).
}

O relato desse servidor nos mostra que ele utilizou de tratamentos complementares à alopatia, com base em seus próprios conhecimentos e obteve resultados positivos. Essa visão do participante 3 nos recorda o que diz o Ministério da Saúde do Governo Brasileiro, que define as PICS como tratamentos terapêuticos, fundamentados em conhecimentos tradicionais que buscam prevenir doenças como a depressão e, em alguns casos, tratar doenças crônicas (BRASIL, 20--). Tal situação nos leva a crer que quanto mais esse tipo de recurso for difundido, acessível e utilizado, mais perto estaremos de reduzir o adoecimento no ambiente de trabalho de forma saudável e educativa, visto que ele é uma espécie de reeducação de hábitos que não só soluciona problemas de saúde, mas também evita que eles ocorram.

O participante 10 alega ter vivenciado episódio de arritmia - para o qual realizou tratamentos alopáticos até voltar à normalidade - e problemas respiratórios que, segundo ele, é um caso crônico, mas que se agravou por lidar diariamente com processos em papel antigo, precisando utilizar medicamentos para alergia várias vezes. Este, por sua vez, recorreu aos medicamentos convencionais e também obteve bons resultados, mas, conforme diz, esse processo de adoecimento se repetiu diversas vezes e, por estar participando da GL, infere-se que ele acredita no auxílio que essa atividade pode trazer para a melhoria de sua saúde. O participante 8 , que também diz ter sofrido com a arritmia, não explicita se algum tratamento foi 
realizado, mas completa que foi sentida uma única vez, devido a uma crise de ansiedade, um dos sintomas relacionados por Piolli, Silva e Heloani (2015) ao adoecimento laboral.

Dois participantes relataram sentir dores na coluna e dores musculares, mas afirmam que não realizaram tratamentos, pois eram dores esporádicas. O participante 20, que também sentiu dores musculares e na coluna, conta que realizou tratamento fisioterápico por seis meses. Outros dois que afirmam sentir essas mesmas dores, juntamente com problemas de pele e problemas digestivos/gástricos, indicam que as mesmas são constantes, mas não mencionam nenhum tratamento. O participante 6 apresentou problemas digestivos/gástricos, acompanhados de dores no pulso e na mão direita e realizou tratamento fisioterápico por aproximadamente um ano.

Em seguida, buscou-se conhecer os sintomas emocionais do adoecimento laboral desses servidores - podendo, novamente, o mesmo servidor marcar mais de uma opção - gerando o seguinte panorama: 8 dizem sofrer com a ansiedade, 7 com o estresse, 7 com a desmotivação, 7 com o cansaço, 3 com a instabilidade emocional, 3 com a angústia, 1 com a depressão, 1 com o medo e 1 com cefaleias. Vale ressaltar aqui a afirmação de Rabelo, Silva e Lima (2018) sobre a psicossomatização traduzir-se na transmissão da aflição sofrida no ambiente de trabalho para sintomas físicos.

Após conhecer os sintomas físicos e emocionais, procurou-se entender suas percepções sobre a relação desses sintomas com suas atividades laborais e, por quase unanimidade somente o participante 25 respondeu negativamente e o participante 28 não desacredita totalmente, mas indica que situações fora do trabalho também os pode causar, porém não trazem nenhuma justificativa para seus pontos de vista - verificou-se que $85 \%$ dos participantes acreditam na relação trabalho - adoecimento. Conforme afirma um dos participantes:

\footnotetext{
Sim, sempre trabalhei com atividades administrativas, essa função é estressante e muitas vezes ocasiona algum sintoma físico e emocional que precisa de atenção. Como comentei acima, acredito que tanto as dores físicas, quanto os sentimentos estão interligados, as ações precisam ser conjuntas para solucioná-los. Para isto adotei acompanhamento médico ocasional, uso de medicamentos ocasionais, redefinição da rotina no trabalho, revisão de prioridades, atividades laborais, como pausas regulares a cada 90 minutos de atividades, uma alimentação mais equilibrada, etc. (participante $3)$.
}

Ao utilizar o trecho "as ações precisam ser conjuntas para solucioná-los" o participante 3 apresenta o apelo que existe em nosso sistema trabalhista por um tratamento completo do

Revista Expectativa, Toledo/PR, v.20, n. 2, p. 26-50, abr./jun., 2021. 
adoecimento laboral, considerando-se o indivíduo em sua totalidade (corpo, mente e alma), pois esse adoecimento está ligado ao desequilíbrio de uma de nossas forças e não a um fator isolado. Inclusive, essa foi uma questão destacada por Souza e Luz (2009) ao falar sobre o surgimento das PICS que se deu entre os anos 60 e 70, de acordo com as necessidades que se manifestavam naquele momento e que ainda perduram em nossa sociedade.

O participante 10 conclui que a vida profissional e social caminham juntas e, normalmente, uma influencia a outra. Corroborando com essa ideia, o participante 14 afirma que, por ser necessário interagir com diversas pessoas, de diversas personalidades, esses sintomas estão sim relacionados à sua atividade laboral. Três desses servidores relacionam esses sintomas à carga excessiva de trabalho e à enorme responsabilidade que carregam sobre ela. $\mathrm{E}$, por fim, o participante 30 afirma que os relaciona ao assédio moral sofrido por parte de chefias.

Tudo isso nos mostra claramente que esses servidores sentem diariamente os efeitos de um sistema trabalhista falho, que trata o ser humano como uma máquina, que trabalha oito horas (ou mais) por dia, ultrapassando os limites do corpo; fato magistralmente descrito pela "hipersolicitação" realizada aos trabalhadores, definida por Cardoso (2015). Esses fatores se acumulam até refletirem em sua saúde e, clamando por solução, buscam então atividades como a GL.

Após traçar esse diagnóstico, foi apurado que $40 \%$ dos participantes não conheciam o termo "práticas integrativas" antes de participar dessa pesquisa. Em seguida, foi apresentada uma lista com diversas PICS, na qual os servidores poderiam marcar todas as que já realizaram, além de ser dado espaço para comentarem como foram as experiências. Tivemos então os seguintes resultados: 5 já fizeram uso da homeopatia, 4 da osteopatia - um dos que marcaram essa opção complementa que ela foi fundamental para auxiliar nos momentos de crise de dores musculares -, 3 da aromaterapia, 3 de florais, 2 da meditação, 2 da medicina tradicional chinesa, 2 da yoga, 2 do reiki, 1 da biodança, 1 da musicoterapia - acrescentando que a inclui em momentos de descanso e relaxamento - e 1 da acupuntura e ventosaterapia, sendo esta última caracterizada por ele como excelente para o alívio das dores. Em geral, os participantes comentam que a utilização das PICS proporciona experiências positivas. Essas respostas apontam que mesmo que uma boa parte não conheça o conceito de práticas integrativas em si, todos os participantes já realizaram alguma das PICS ou alguma atividade que englobe suas características e fundamentos.

Revista Expectativa, Toledo/PR, v.20, n. 2, p. 26-50, abr./jun., 2021. 
Foram questionados se, a partir de seus conhecimentos prévios e do que foi exposto nos questionários, consideram a ginástica laboral como uma prática integrativa. Todos respondem que sim, mas três ressaltam que a GL ofertada pelo Projeto SuperAção não cumpre integralmente com a proposta da prática integrativa, reafirmando as questões já apontadas no questionário anterior, como falta de preparo dos estagiários, foco restrito ao físico e poucas ações de integração da equipe.

Em seguida, foi perguntado se consideram que essas práticas podem ser utilizadas como amenizadoras do processo de adoecimento laboral e como isso pode ocorrer. E, novamente, todos respondem que sim. Conforme o participante 3 diz: "Sim, principalmente com a integração dessas práticas no ambiente de trabalho, como por exemplo: música ambiente, objetos de arte para melhorar a visibilidade do local, plantas, aromas especiais com a finalidade de relaxamento, etc." (participante 3).

Logo, observa-se que sim, a GL é considerada por esses servidores como uma prática integrativa, principalmente por proporcionar alívio nas dores físicas, sofrimentos mentais e emocionais e melhorias na qualidade de vida. No entanto, a GL ofertada na PGP precisa, na percepção do seu público-alvo, de alguns aprimoramentos para se adequar ao conceito de "prática integrativa", especialmente no que tange à totalidade do cuidado aos três "pilares" da saúde (corpo, mente e alma), defendida por Fischborn et al. (2016) como a principal característica das PICS.

Por fim, foram indagados sobre como avaliam o conceito "trabalho" na nossa contemporaneidade e se consideram que deveria haver modificações em nosso sistema trabalhista. $\mathrm{O}$ resultado nos permitiu observar que todos os entrevistados consideram que deve sim haver mudanças. O participante 6, por exemplo, indica que essas alterações devem ser feitas especialmente na carga horária, contendo maior flexibilização dessa. Já o participante 2 acredita que a atividade laboral de hoje é muito dependente do uso da internet e, por isso, o Home office é uma opção que deve ser aplicada, sempre que possível. Em complemento, o participante 3 afirma:

Atualmente o conceito de trabalho é muito pautado no significado mecânico, onde está relacionado com o esforço feito por indivíduos para o alcance de determinado objetivo, esse esforço pode ser mental ou corporal. Sim, deveria ter modificações no sentido de tratar o homem como ser humano e não como parte de uma engrenagem, é necessário mais qualidade de vida no trabalho, para se ter pessoas mais engajadas, comprometidas e principalmente saudáveis (participante 3 ).

Revista Expectativa, Toledo/PR, v.20, n. 2, p. 26-50, abr./jun., 2021. 
Vale ressaltar que essa colocação sobre o trabalho remoto foi realizada pelo participante 2 apenas 11 dias antes dele se tornar parte da rotina desses servidores.

O mundo começou a sofrer com o novo coronavírus (COVID-19) por volta de dezembro de 2019, até que se tornou uma pandemia e instaurou medo, caos, insegurança e incerteza na população mundial. Em 21 de março de 2020, foi decretado, como forma de combate ao vírus, o confinamento da população Viçosense, conforme ocorreu no mundo inteiro, tornando o Home office uma realidade de muitos desses servidores. Essa alteração no cotidiano trouxe inúmeros desafios, problemas econômicos e sociais inimagináveis e que serão difíceis de solucionar, mas o mundo foi obrigado a parar, respirar e se reinventar. O trabalho, daqui em diante, não poderá mais ser visto como o bem mais precioso que temos, ele está dando espaço para o foco se tornar a saúde e bem-estar do ser humano. Acreditamos que está, nesse caos, a oportunidade de reinventarmos esse quadro desordenado, como descrito pelos participantes dessa pesquisa, cenário em que vivemos e achamos normal por muito tempo, mas do qual sentimos cada vez mais os efeitos e a necessidade de mudança.

\section{CONSIDERAÇÕES FINAIS}

Tendo em vista as inúmeras falhas existentes em nosso sistema trabalhista, este trabalho trouxe como contribuição social e acadêmica a maior visibilidade de uma dessas: o adoecimento no ambiente laboral acompanhada da sugestão de uma possibilidade de solução. Buscou-se então verificar quais são as percepções dos servidores públicos da área administrativa, lotados na Pró-Reitoria de Gestão de Pessoas da Universidade Federal de Viçosa sobre as práticas integrativas e as melhorias proporcionadas à qualidade de vida através da utilização da ginástica laboral. Para responder a esse questionamento, investigou-se se o ambiente de trabalho pode ser conceituado como espaço adoecedor, se as práticas integrativas podem ser utilizadas para amenizar o adoecimento laboral e se a GL é entendida por esses servidores como uma prática integrativa.

Para criar uma relação de "expectativa (teoria) X realidade (prática)" procurou-se analisar o fenômeno em questão, à luz do arcabouço teórico juntamente com a revisão do Projeto SuperAção. Isso pela perspectiva dos próprios servidores, uma vez que são eles que

Revista Expectativa, Toledo/PR, v.20, n. 2, p. 26-50, abr./jun., 2021. 
estão diariamente expostos aos efeitos negativos que o trabalho pode trazer e buscam formas de amenizá-lo, sendo nesse caso por meio da GL.

Em resposta, encontramos o fato de que sim, o ambiente de trabalho é um espaço adoecedor, pois o atual sistema trabalhista exige do funcionário muito além do que seu corpo pode suportar, isto é, seu dia a dia fica sobrecarregado com prazos curtos, enorme volume de tarefas e responsabilidades; gerando, assim, a psicossomatização desses problemas, que se reflete em sintomas físicos e emocionais, consequentemente, reduzindo sua produtividade. Logo, vê-se que este é um empecilho tanto para a qualidade de vida dos empregados quanto para o empregador, dado que pouca produtividade significa menor eficiência organizacional.

Constatamos então que uma forma de amenizar esses impactos é utilizando as práticas integrativas, pois elas configuram um tipo de técnica alternativa à alopatia que atua tanto na prevenção, quanto no tratamento do adoecimento laboral, posto que elas operam a partir do cuidado total ao bem-estar do ser humano, englobando os três pilares da saúde: corpo, mente e alma. Porém, apuramos que, por mais que os fundamentos das PICS sejam conhecidos e, até mesmo utilizados por grande parte desses servidores, seus conceitos ainda são pouco divulgados, o que impede que seus efeitos positivos sejam ofertados a boa parte da população. Em vista disso, torna-se necessário disseminar mais os benefícios das PICS e como devem ser utilizadas.

Conforme averiguado, a ginástica laboral pode sim ser considerada uma prática integrativa, pois possui todas as características das PICS e promove melhorias na qualidade de vida, tanto na saúde mental/emocional quanto na saúde física. No entanto, a GL ofertada pelo Projeto SuperAção apresenta falhas em alguns pontos que precisam ser corrigidos para obter maior eficiência, eficácia e garantir a continuidade desse projeto tão importante. Sugere-se, por conseguinte, que seja feita uma reavaliação constante do projeto, acompanhada de uma análise minuciosa dos feedbacks dos servidores que a praticam, buscando compreender ainda mais suas necessidades e opiniões, principalmente no que tange à forma como os profissionais contratados para acompanhamento aplicam a prática.

Foi confirmado também a partir de colocações dos participantes dessa pesquisa que nosso sistema trabalhista precisa de revisão, principalmente em relação à carga horária. Destacamos que a situação da pandemia do COVID-19 que o mundo enfrenta hoje trouxe à tona essa realidade e exigiu mudanças imediatas nesse cenário. Destarte, deixamos como 
sugestão para pesquisas futuras as mudanças que precisam ocorrer no nosso sistema trabalhista para garantir o equilíbrio entre a qualidade de vida do trabalhador e a eficiência organizacional.

\section{REFERÊNCIAS}

ABERGO - Associação Brasileira de Ergonomia. O que é ergonomia? [20--]. Disponível em: http://www.abergo.org.br/internas.php?pg=o_que_e_ergonomia. Acesso em: 09 fev. 2020.

ALVES, M. A.; BLIKSTEIN, I. Análise da narrativa. In: GODOI, C. K.; BANDEIRA-DEMELO, R.; DA SILVA, A. B. (Org.). Pesquisa qualitativa em estudos organizacionais: paradigmas, estratégias e métodos. 2 ed., São Paulo: Saraiva, 2010. 480p.

BRASIL. Ministério da Saúde. Práticas Integrativas e Complementares (PICS): quais são e para que servem. [20--]. Disponível em: https://saude.gov.br/saude-de-a-z/praticasintegrativas-e-complementares. Acesso em: 07 fev. 2020.

CARDOSO, A. C. M. CARDOSO, Ana Claudia Moreira. O trabalho como determinante do processo saúde-doença. Tempo Social, v. 27, n. 1, p. 73-93, 2015. Disponível em: http://dx.doi.org/10.1590/0103-207020150110. Acesso em: 07 fev. 2020.

CRPG - Centro de Reabilitação Profissional de Gaia. O que é a ergonomia?. 2012.

Disponível em: http://www.crpg.pt/empresas/recursos/kitergonomia/Paginas/ergonomia.aspx. Acesso em: 09 fev. 2020.

FALEIROS, F. et al. Uso de questionário online e divulgação virtual como estratégia de coleta de dados em estudos científicos. Texto \& Contexto-Enfermagem, v. 25, n. 4, 2016. Disponível em: https://www.scielo.br/scielo.php?pid=S010407072016000400304\&script=sci_arttext\&tlng=pt . Acesso em: 16 mar. 2020.

FISCHBORN, A. F. et al. A Política das práticas integrativas e complementares do SUS: o relato da implementação em uma unidade de ensino e serviço de saúde. Cinergis, v. 17, 2016. Disponível em: https://online.unisc.br/seer/index.php/cinergis/article/view/8149/5358. Acesso em: 07 fev. 2020.

FREITAG, R. M. Amostras sociolinguísticas: probabilísticas ou por conveniência? Revista de Estudos da Linguagem, v. 26, n. 2, p. 667-686, 2018. Disponível em: https://core.ac.uk/download/pdf/205452684.pdf. Acesso em: 23 set. 2020.

GODOY, A. S. Pesquisa qualitativa: Tipos fundamentais. Revista de Administração de empresas, p. 20-29, 1995. Disponível em: https://www.scielo.br/pdf/rae/v35n3/a04v35n3.pdf. Acesso em: 07 mar. 2020.

LABOV, W. Language in the inner city: studies in the black english vernacular. Philadelphia: Pensylvannia University Press, 1972. 412p. 
MARTINS, C. de O. Efeitos da ginástica laboral em servidores da reitoria da UFSC. 2000. 109 f. Dissertação (Mestrado) - Curso de Engenharia de Produção, Universidade Federal de Santa Catarina, Florianópolis, 2000. Disponível em: https://repositorio.ufsc.br/bitstream/handle/123456789/78314/170539.pdf?sequence=1\&isAll owed=y. Acesso em: 09 fev. 2020.

MIGUEL, P. A. C. Estudo de caso na engenharia de produção: estruturação e recomendações para sua condução. Production, v. 17, n. 1, p. 216-229, 2007. Disponível em:

http://www.scielo.br/scielo.php?script=sci_arttext\&pid=S0103-

65132007000100015\&lng=en\&nrm=iso. Acesso em: 21 mar. 2020.

MOREIRA, D. A. O método fenomenológico na pesquisa. São Paulo: Thomson Pioneira, 2002, 152 p.

PGP - UVF. Pró-Reitoria de Gestão de Pessoas - Universidade Federal de Viçosa. Atividades e Vagas do "Projeto Superação - Atividades físicas para servidores da UFV". [20--].

Disponível em: http://www.pgp.ufv.br/?noticias=atividades-e-vagas-do-projeto-superacaoatividades-fisicas-para-servidores-da-ufv. Acesso em: 09 fev. 2020.

PIOLLI, E.; SILVA, E. P.; HELOANI, J. R. M. Plano nacional de educação, autonomia controlada e adoecimento do professor. Cadernos Cedes, v. 35, n. 97, p. 589-607, 2015. Disponível em: https://www.scielo.br/scielo.php?pid=S0101-

32622015000300589\&script=sci_arttext. Acesso em: 09 fev. 2020.

POLETTO, S. S. Avaliação e implantação de programas de ginástica laboral, implicações metodológicas. 2002. 146 f. Dissertação (Mestrado) - Curso de Engenharia de Produção, Universidade Federal do Rio Grande do Sul, Porto Alegre, 2002. Disponível em: https://www.lume.ufrgs.br/handle/10183/2488. Acesso em: 09 fev. 2020.

RABELO, L. Di B. C.; SILVA, J. M. A.; LIMA, M. E. A. Trabalho e adoecimento psicossomático: reflexões sobre o problema do nexo causal. Psicologia: ciência e profissão, v. 38, n. 1, p. 116-128, 2018. Disponível em:

https://dialnet.unirioja.es/servlet/articulo?codigo=6385434. Acesso em: 06 fev. 2020.

SARAIVA, A. M.; FERREIRA FILHA, M. de O.; DIAS, M.D. As práticas integrativas como forma de complementaridade ao modelo biomédico: concepções de cuidadoras. Revista de Pesquisa Cuidado é Fundamental Online, v. 3, p. 155-163, 2011. Disponível em: https://www.redalyc.org/pdf/5057/505750891019.pdf. Acesso em: 25 fev. 2020.

SOUZA, E. F. A. A. de; LUZ, M. T. Bases socioculturais das práticas terapêuticas alternativas. História, Ciências, Saúde-Manguinhos, v. 16, n. 2, p. 393-405, 2009. Disponível em: https://www.scielo.br/scielo.php?pid=S010459702009000200007\&script=sci_arttext Acesso em: 19 fev. 2020.

TODOROV, T. Grammaire du Decameron. Netherlands: Mouton Publishers, the Hague, 1969. 100p. 